\title{
Evaluación Histológica e Histoquímica de las Fibras Colágenas y Elásticas de los Tejidos de la ATM Humana
}

\author{
Histological and Histochemical Evaluation of Collagen \\ and Elastic Fibers in Human TMJ Tissue
}

\author{
Rocío Oyanguren Figueroa*; Rosa Wurgaft Dreiman** \& María Angélica Montenegro Rizzardini***
}

OYANGUREN, F. R.; WURGAFT, D. R. \& MONTENEGRO, R. M. A. Evaluación histológica e histoquímica de las fibras colágenas y elásticas de los tejidos de la ATM humana. Int. J. Odontostomat., 4(3):277-284, 2010.

RESUMEN: Se estudió la cantidad y distribución de las fibras colágenas y elásticas de los distintos tejidos que conforman la articulación témporomandibular humana (ATM). Se utilizaron diecisiete ATMs humanas. Las muestras fueron procesadas con técnicas histológicas e histoquímicas. Al evaluar la morfología articular, ocho presentaron características histológicas normales y nueve alteradas. La cantidad y distribución de fibras elásticas varió para cada tejido articular en estudio, siendo notable la cantidad de fibras elásticas en la zona anterior y retrodiscal. Se determinó gran cantidad de fibras colágenas tipo I en todos los tejidos articulares. Entre los manojos de colágeno I se encontraron fibras de colágeno tipo III. Estos hallazgos nos indican que la cantidad y distribución de estas fibras están relacionadas con el rol funcional de los tejidos articulares donde ellas se encuentran. No se encontraron diferencias significativas en la cantidad de fibras elásticas, colágenas tipo I y III entre los tejidos conectivos evaluados en articulaciones sanas y enfermas.

PALABRAS CLAVE: fibras elásticas, fibras colágenas, disco articular, ATM.

\section{INTRODUCCIÓN}

La articulación témporomandibular (ATM) es un elemento primordial en el funcionamiento del sistema estomatognático. Las características morfológicas de las estructuras que la componen son muy importantes en el funcionamiento articular y alteraciones en su morfología determinan alteración de los movimientos articulares (Okeson, 1995).

Los tejidos conectivos, cartílago y hueso que estucturan la ATM están formados por las células propias del tejido y la matriz extracelular (MEC) fibrilar y amorfa.

Diversos estudios sobre las características histológicas de estos tejidos y los elementos que lo forman indican modificaciones con relación a condiciones biomecánicas a las que están sometidas y una gran capacidad de remodelación tisular y cambios en la concentración de macromoléculas específicas en los tejidos articulares, en relación a cambios oclusales (Wurgaft \& Montenegro, 2003; Wurgaft et al., 2001).

Estos cambios han sido reportados también si existen condiciones patológicas (Axelsson et al., 1992).

Se ha demostrado que la inducción de desplazamientos discales anteriores en animales de experimentación produce alteraciones en la cantidad de proteoglicanos como keratansulfato, condroitin-4sulfato, condroitin-6-sulfato y ácido hialurónico, cambios que son similares a los producidos en otras articulaciones sinoviales (Ali \& Sharawy, 1996).

Estudios en seres humanos, con desplazamientos discales sin reducción se ha reportado fragmenta-

\footnotetext{
Cirujano dentista, ejercicio en atención primaria de salud Servicio de Salud Metropolitano Sur comuna el Bosque, alumna diplomado de Oclusión clínica UNAB 2010, Chile.

* Cirujano dentista, profesor Histología y Embriología Facultad de Medicina Universidad de Chile, profesora de post grado en Fisiopatología Maxilofacial y Patología Articular UNAB, Chile.

${ }^{* * *}$ Cirujano dentista, Profesora de Histología y Embriología, U. Finis Terrae y Diego Portales, Chile.
} 
ción de fibras colágenas, degeneración hialina de la matriz del disco, proliferación de células tipo condrocitos y hasta cambios fenotípicos en las poblaciones celulares que conforman los tejidos de la ATM (Leonardi et al., 2007).

Morfológicamente, a nivel del disco articular y de la cubierta fibrosa que tapiza las superficies articulares, se ha descrito la presencia de fibras colágenas tipo I agrupadas preferentemente en manojos. Según Scapino et al. (2006) principalmente la disposición de los manojos de colágeno es paralelo a la superficie del tejido discal. En la zona anterior y posterior del disco existiría una cantidad de fibras colágenas dispuestas de manera vertical, que ayudarían a distribuir el stress durante la función mandibular, los cuales podrían ser sitios de mayor compresión.

Las fibras elásticas acompañan a las fibras colágenas en distintas proporciones en el tejido discal.

En disecciones del disco de la articulación témporomandibular realizados en conejos, se apreció un incremento de fibras elásticas en el cóndilo y eminencia articular del temporal al cabo de un mes de realizada la disección. La evaluación morfológica después de tres meses de la disección mostró una leve disminución en las cantidades de fibras elásticas tanto en el cóndilo como en la eminencia articular (Sato et al., 2002).

Existe poca información sobre la cantidad, distribución y función de las fibras elásticas en la ATM humana. Se han descrito fibras elásticas en la zona anterior del disco articular. En la zona posterior del disco las fibras se disponen alrededor de los manojos o fibras colágenas tipo I. Hay estudios que demuestran la ausencia de fibras elásticas en la zona media (Clément et al., 2006). En la zona retrodiscal se encuentran gruesos manojos de fibras colágenas y elásticas en la zona superior, mientras que en la zona inferior se encuentran en poca cantidad.

Según algunos autores, la zona superior de la zona retrodiscal, rica en estas fibras, actuaría como antagonista del movimiento anterior del disco, dándole de esa manera un rol funcional a estas fibras (Kino et al., 1993).

Para Clément et al. el estrato inferior de la zona retrodiscal se comportaría como un aparato hidráulico, dentro del cual las fibras redistribuirían de manera rápida el líquido sinovial necesario para mantener la morfología y la adaptación de las superficies articulares durante los movimientos funcionales de ésta.

Debido a los escasos antecedentes existentes respecto al tema, se pretende evaluar la distribución de las fibras colágenas y elásticas de los tejidos conectivos presentes en la ATM, cubiertas fibrosas, las membranas sinoviales y la cápsula articular y analizar la posible relación morfofuncional de los tejidos que forman esta compleja articulación.

\section{MATERIAL Y MÉTODO}

Se utilizaron diecisiete preparaciones de articulaciones témporomandibulares humanas incluidas en parafina histológica provenientes de los archivos del Laboratorio del Programa de Anatomía y Biología del Desarrollo, del Instituto de Ciencias Biomédicas de la Facultad de Medicina, de la Universidad de Chile.

A las muestras incluidas se le realizaron cortes seriados de $6 \mu \mathrm{m}$, las cuales fueron procesados con las técnicas histológicas de hematoxilina eosina, tricrómico de Masson.

Se evaluaron histoquímicamente catorce articulaciones témporomandibulares humanas, para identificar la presencia de fibras elásticas y colágenas, en los tejidos articulares que se encuentran íntegros.

La técnica de picrosirius se utilizó para la observación selectiva del colágeno tipo I y III bajo el microscopio de polarización y con la técnica orceína se reveló la presencia de fibras elásticas.

Para determinar la cantidad de fibras elásticas se utilizaron cruces para estereotipar:

- = Nula cantidad.

$+=$ Leve cantidad.

$++=$ Regular cantidad .

$+++=$ Abundante cantidad .

\section{RESULTADOS}

De los diecisiete casos estudiados, ocho presentaron características histológicas normales y los otros nueve, características histológicas alteradas.

De los casos sin alteraciones el cóndilo está for- 
mado por tejido óseo compacto laminillar en su superficie y hacia la profundidad por tejido óseo esponjoso. El disco articular está constituido por tejido conectivo fibroso, con manojos de fibras colágenas de diferente orientación con mayor densidad en la zona media. En la zona anterior, el colágeno se relaciona con los fascículos del músculo pterigoídeo lateral. La zona retrodiscal es un tejido conectivo laxo con abundantes fibras elásticas y colágenas.

Se encontraron islotes de tejido cartilaginoso a lo largo de todo el disco, siendo más abundante en la zona media, área de mayor trabajo.

La superficie articular del temporal esta constituido por tejido óseo compacto periférico y esponjoso es su parte interna.

De los casos con alteraciones, dos de los casos estudiados presentaron perforaciones discales evidentes, cinco de ellos presentaron como rasgo patológico común la presencia de vasos sanguíneos en la zona media discal y tejido inflamatorio en el tejido medular del hueso esponjoso condilar. En algunos de estos casos además de la osteoartritis, se veían grietas en la superficie articular del hueso condilar y en algunos casos pérdida ósea, lo que indicaba un fenómeno de osteoartrosis. Tres casos presentaron pérdida de tejido óseo compacto a nivel del cóndilo mandibular, osteoartrosis.

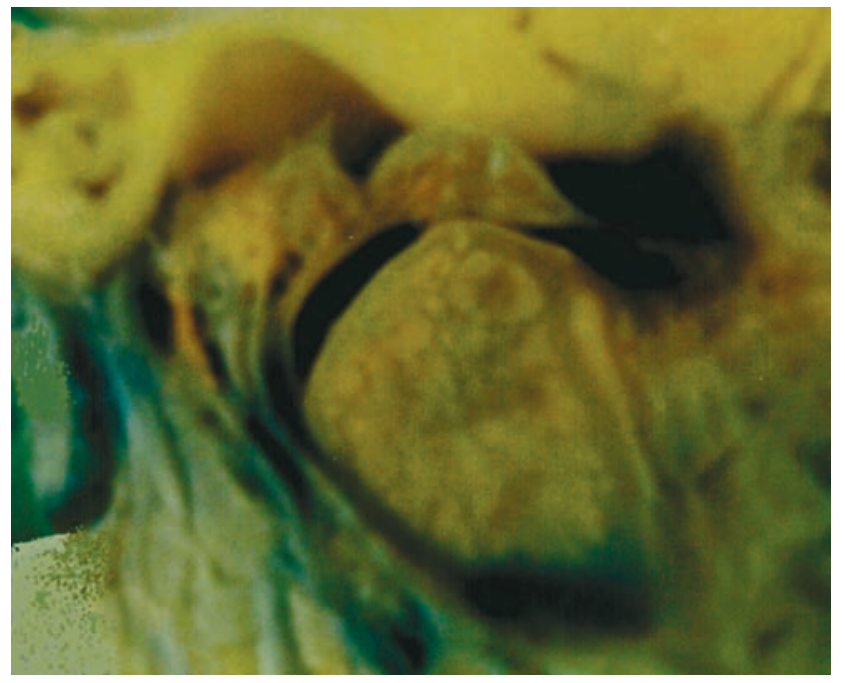

Al examen macroscópico se detectaron tres casos con desplazamiento del disco. Dos casos presentaron un desplazamiento anterior del disco, en estos casos la zona anterior era más delgada y la zona posterior se encontraba enfrentando al polo medial del cóndilo mandibular. Otro caso con un desplazamiento posterior del disco, presentaba una fisura en la zona media del tejido discal, con adherencia del disco en el sector posterosuperior. (Fig. 1a).

En siete casos estudiados se observaron zonas homogéneas (hialinas) en el tejido fibroso discal donde se observó escasas fibras colágenas.

La cantidad y distribución de fibras elásticas a nivel del tejido fibroso que reviste todo el cóndilo mandibular (zona de trabajo y zona lateral) fue de leve a mediana cantidad. No se encontraron diferencias significativas entre casos sanos y enfermos, sólo en un caso con patología articular se encontraron abundantes fibras elásticas de la cubierta fibrosa del tejido condilar. Las fibras elásticas se observaron en mayor cantidad en la profundidad de la cubierta fibrosa, en la superficie se disponen en forma paralela a las fibras colágenas (Fig. 2).

En el temporal, se evaluó la eminencia articular en siete de los catorce casos, seis de ellos eran articulaciones sanas. En dos articulaciones una sana y otra enferma se encontró mediana cantidad de fibras elásticas y en las otras cinco articulaciones se observó leve cantidad de estas fibras, distribuyéndose paralelas a las fibras colágenas del tejido.

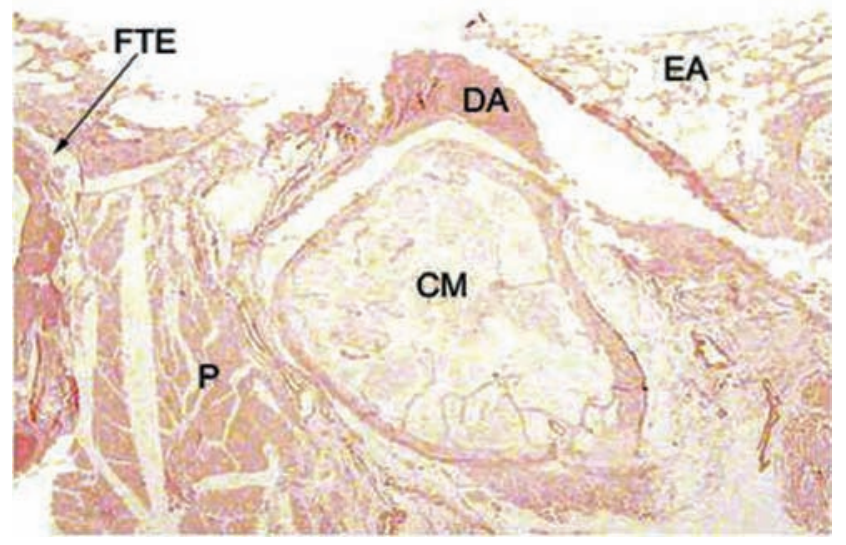

Fig. 1 Corte anatómico en sentido sagital de una ATM alterada.

A. Visión macroscópica, se observa el cóndilo mandibular, la fosa y eminencia articular del temporal y el disco fisurado con desplazamiento posterior y adherencia.

B. Se observan fibras elásticas como elementos fibrilares de color café oscuro en la zona retrodiscal, la fisura timpanoescamosa (FTE), la glándula parótida ( $P$ ), el cóndilo mandibular (CM), el disco articular ( DA) y la eminencia articular (EA). Tinción Orceína, aumento lupa. 


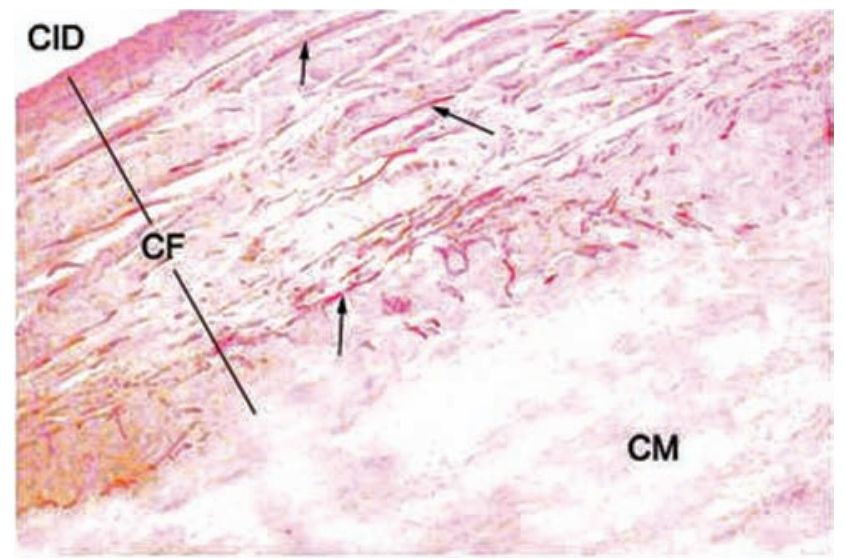

Fig. 2. Cubierta fibrosa de la zona de trabajo condilar (CF). Presenta mediana cantidad de fibras elásticas (flechas). Sobre esta cubierta se muestra el compartimento infradiscal (CID) y el cóndilo mandibular (CM), al cual reviste. Tinción Orceína 40x.

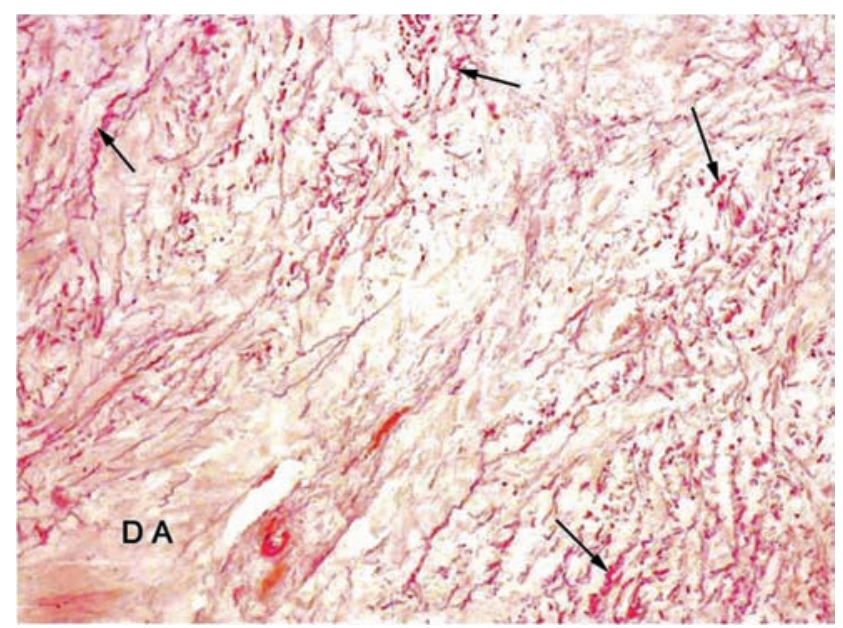

Fig. 3. Tejido fibroso de la zona anterior del disco articular (DA). Presenta abundante cantidad de fibras elásticas (flechas). Tinción Orceína 10x.

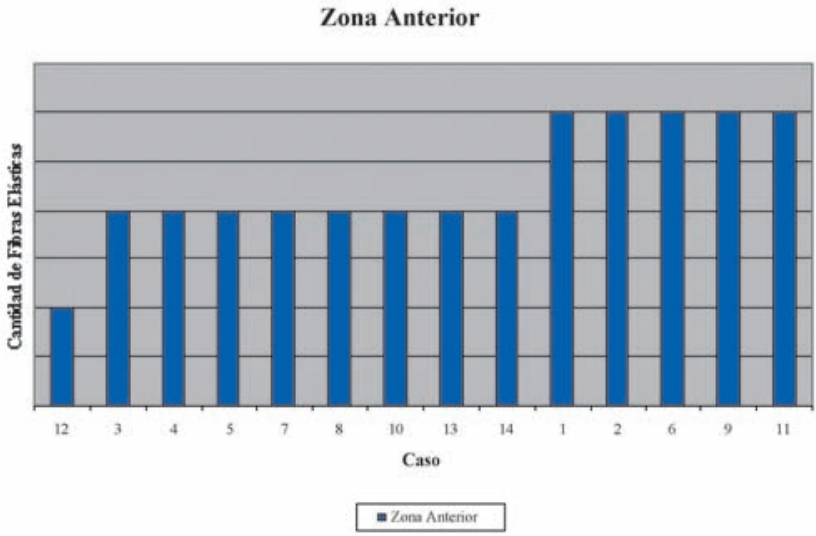

Fig. 4. Muestra la cantidad de fibras elásticas en la zona anterior del disco articular, en los casos evaluados.
La fosa articular del temporal se evaluó en diez de los catorce casos, de los cuales tres presentaron mediana cantidad, cinco leve y dos no presentaron. No hubo diferencia entre casos sanos y enfermos.

En el disco articular, en la zona anterior la cantidad de fibras elásticas fue de mediana (cinco casos) a abundante cantidad (ocho casos), siendo un solo caso de leve cantidad. La distribución de las fibras elásticas se observó en todas las direcciones (Figs. 3 y 4 )

No se observaron diferencias significativas en la distribución de fibras elásticas del disco en los casos sanos y articulaciones alteradas.

En la zona media discal se evaluaron doce articulaciones, la cantidad de fibras elásticas encontradas fue de mediana cantidad en cinco casos y leve cantidad en seis casos, un sólo caso no presentó fibras elásticas. No hubo diferencias entre casos sanos y alterados.

En la zona posterior se encontraron cinco casos con mediana cantidad, siete casos, con leve cantidad y sólo dos casos presentaron abundante cantidad de fibras elásticas que corresponden a casos enfermos. Las fibras elásticas se distribuyen en todas direcciones en esta zona discal en todos los casos evaluados.

En la zona retrodiscal los catorce casos presentaron abundante cantidad de fibras elásticas, tanto en casos sanos y enfermos.

La distribución de estas fibras en la zona retrodiscal es en todas direcciones y a veces unidas formando cordones fibrosos (Fig. 5).

En la zona anterior y retrodiscal del tejido laxo del disco, encontramos gran cantidad de fibras elásticas en la pared de vasos sanguíneos de todo calibre. Esta distribución se observó en pacientes sanos y con patología articular (Fig. 1 b).

En seis articulaciones se evaluó la cantidad de fibras elásticas en la membrana sinovial, encontrándose en cuatro casos mediana cantidad y en dos casos abundante cantidad de estas fibras. La distribución de las fibras elásticas es paralela a las fibras colágenas.

A nivel de la cápsula articular se observaron sólo cinco de los catorce casos, dentro de los cuales 


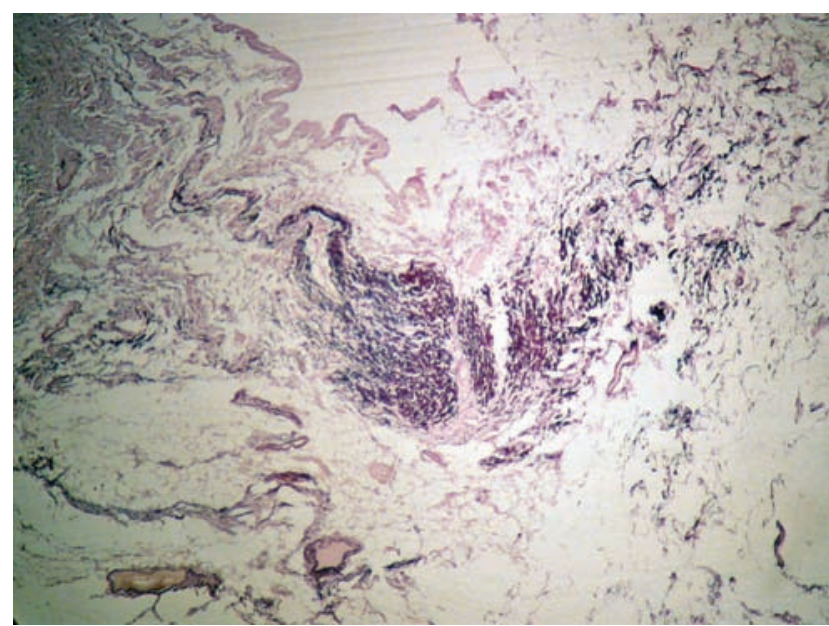

Fig. 5. Muestra la distribución de fibras elásticas en el tejido retrodiscal del disco articular. Se observan manojos fibrilares elásticos café oscuro en el tejido y algunas fibras elásticas en la pared de los vasos sanguíneos. Tinción Orceína. 40x

cuatro presentaron abundante cantidad de fibras elásticas y uno leve, corriendo estas paralelas a las fibras colágenas que forman la cápsula.

La evaluación de las fibras elásticas de la membrana sinovial y de la cápsula articular fue similar para casos sanos y enfermos.

En todos los tejidos conectivos evaluados la mayoría de las fibras colágenas observadas eran fibras

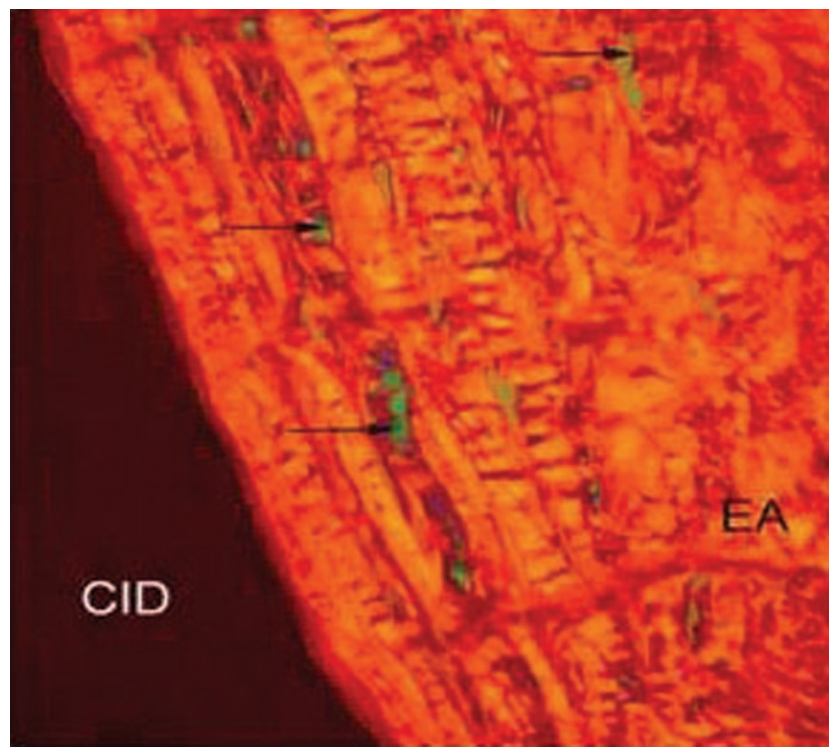

Fig. 6. Tejido fibroso de la eminencia articular del temporal (EA). Las flechas indican las fibras colágenas tipo III sobre el colágeno tipo I teñido de rojo en el fondo. Tinción Picrosirius bajo microscopio de Polarización 20x. tipo I, sólo se observaron algunas fibras colágenas tipo III entre los manojos de colágeno tipo I.

Con respecto a la cantidad y distribución de fibras colágenas en las superficies articulares del cóndilo y el temporal la distribución de las fibras colágenas tipo I fue paralela a la superficie del tejido fibroso. El colágeno tipo III se encontró en escasa cantidad entre las fibras de colágeno tipo I siguiendo su misma dirección (Fig. 6).

En la zona anterior, media y posterior del disco articular, las fibras colágenas tipo I se encuentran en todas direcciones, con escasa cantidad de fibras tipo III entre ellas.

En la zona retrodiscal las fibras colágenas tipo I forman parte del tejido conectivo laxo de la zona, distribuidas en todas direcciones.

En la membrana sinovial y la cápsula articular las fibras colágenas tipo III fueron escasas y se distribuyen entre las fibras las colágenas tipo I.

No se observaron diferencias significativas entres los casos sanos y enfermos.

\section{DISCUSIÓN}

Con las técnicas histológicas utilizadas se evaluó la morfología de los tejidos de la ATM y con las técnicas histoquímicas vimos la cantidad y distribución de las fibras colágenas y elásticas en los tejidos articulares.

En la eminencia y cóndilo articular se encontró de leve a mediana cantidad de fibras elásticas en el tejido conectivo que cubre las superficies articulares. No se encontraron diferencias significativas en la cantidad de fibras elásticas presentes en las zonas evaluadas.

La cantidad de fibras elásticas encontradas en las zonas de trabajo del cóndilo mandibular, eminencia del temporal, zona lateral condilar y fosa temporal, nos hace pensar que el rol de estas fibras en el tejido fibroso no es preponderante, debido a que la cantidad en que están presentes y su distribución en zonas de mayor y menor carga funcional es similar.

Sato et al., establecen que bajo una situación de sobrecarga funcional frente a la ausencia de tejido 
discal, las cubiertas fibrosas que tapizan las superficies óseas articulares se engrosarían para adaptarse a sus nuevas condiciones funcionales.

En todas las porciones del tejido discal se encontraron fibras elásticas. En la zona anterior del disco se encontró de mediana a gran cantidad de fibras elásticas. La zona anterior discal es la segunda zona del disco en presentar la mayor cantidad de fibras elásticas, seguida del área retrodiscal. Estos resultados coinciden con lo citado por Fujita et al. (2001), donde encontraron gran cantidad de fibras elásticas en la zona anterior del tejido discal de discos desplazados, concluyendo que la presencia de estas fibras en la zona anterior, serían un factor en la génesis del desplazamiento anterior del disco. Esto podría explicar la importancia de la presencia de las fibras elásticas encontradas en la zona anterior del disco articular.

Las fibras elásticas en las distintas zonas del disco se encontraron en todas direcciones, siguiendo la misma distribución de las fibras colágenas. Estos resultados coinciden con lo establecido por Minarelli \& Liberti (1997).

La zona retrodiscal presentó abundante cantidad de fibras elásticas, encontrándose especialmente en la zona superior en forma densa como gruesos manojos. Estos hallazgos coinciden con lo encontrado por Kino et al.

En nuestros resultados observamos que la zona retrodiscal es un tejido conectivo laxo con escasa cantidad de fibras colágenas y gran cantidad de fibras elásticas, distribuídas en manojos y alrededor de los vasos sanguíneos. En la zona superior son abundantes los manojos elásticos, lo que hace pensar en un ligamento elástico, pero en la observación se ve un tejido laxo con gran cantidad de manojos elásticos. En el sector inferior en cambio, la distribución de las fibras elásticas es mayor alrededor de vasos sanguíneos que formando manojos elásticos.

En toda la zona retrodiscal las fibras elásticas participan en la función mecánica del disco articular e hidraúlica de los vasos sanguíneos presentes en esta zona. Los resultados de los estudios de Kino et al. están de acuerdo con nuestros resultados, en cuanto a la distribución de las fibras en la zona retrodiscal. Benigno et al., (2001) considera al tejido retrodiscal, constituido por dos estratos definidos e independientes en el disco articular, como ya ha sido definido anteriormente por diversos autores.

La calidad y ubicación de este tejido conectivo laxo de la zona retrodiscal es de vital importancia para la función del oído, ya que por él atraviesan vasos y nervios relacionados con esta estructura, que penetran por la fisura petrotimpánica (Ramírez et al., 2005).

Bernhardt et al., (2004) y Tuz et al., (2003) en sus estudios establecen que los TTM pueden presentar síntomas a nivel del oído. Bernhardt et al. proponen que la otalgia, vértigo y tinnitus podrían ser resultado de alteraciones estructurales, producto del desplazamiento posterior del cóndilo mandibular, presionando la zona retrodiscal, zona en que se encuentran estructuras nobles como el nervio aurículo temporal, cuerda del tímpano, así como la trompa auditiva y la musculatura del velo del paladar, estructuras que juegan un rol en la fisiología del oído.

La cantidad de fibras elásticas entre los casos sanos y alterados fue similar a excepción de la zona lateral del cóndilo donde se encontró mayor cantidad de fibras en los casos sanos.

Por la dificultad de estudiar tejidos humanos sólo se pudieron evaluar los tejidos de diecisiete ATMs con diferentes características estructurales y en algunos casos no se pudo evaluar ciertos tejidos por la pérdida de material de la muestra. En el futuro nos gustaría aumentar la casuística para consolidar nuestros resultados y entender mejor la morfofisiología de la articulación témporomandibular.

\section{CONCLUSIONES}

Nuestros hallazgos nos indican que la cantidad y distribución de las fibras elásticas y colágenas I y III están relacionadas con el rol funcional de los tejidos articulares donde se encuentran. Sólo en algunas zonas de los tejidos evaluados, no se encontró una relación directa entre la cantidad y distribución de fibras evaluadas y la función efectuada.

No hubo diferencias significativas entre la cantidad de fibras elásticas y colágenas tipo I y III encontradas entre los casos sanos y enfermos en los tejidos conectivos evaluados en la articulación témporomandibular. 
OYANGUREN, F. R.; WURGAFT, D. R. \& MONTENEGRO, R. M. A. Histological and histochemical evaluation of collagen and elastic fibers in human TMJ tissue. Int. J. Odontostomat., 4(3):277-284, 2010.

ABSTRACT: The quantity and distribution of collagen and elastic fibers of seventeen human TMJ tissues were studied. Histological and histochemical methods were used. The histological evaluation showed eight TMJs with normal morphology and nine with joint tissue alterations. Elastic fibers amount and distribution was different in every analyzed articular tissue, noting the amount of elastic fibers in the anterior and retrodiscal zones. A great quantity of type I collagen fibers was found in all the joint tissues. Type III collagen fibers were found among the type I collagen bundles. These findings suggest a relationship between function and the amount and distribution of these fibers. No significant difference was found in the quantity of elastic, collagen type I and III fibers among the connective tissues in healthy and sick joints.

KEY WORDS: collagen fibers, elastic fibers, articular disc, TMJ.

\section{REFERENCIAS BIBLIOGRÁFICAS}

Ali, A. M. \& Sharawy, M. Histochemical and inmunohistochemical studies of the effects of experimental anterior disc displacement on sulfated glycosaminoglycans, hyaluronic acid and link protein of the rabbit craniomandibular joint. J. Oral. Maxillofac. Surg., 54(8):992-1003, 1996.

Axelsson, S.; Holmlund, A. \& Hjerpe, A. Glycosaminoglycans in normal and osteoarthrotic human temporomandibular join disks. Acta Odontol. Scand., 50:113-9, 1992.

Benigno, M.; Azaredo, R. A.; Lemos, J.; König Júnior, B. \& Liberti, E. A. The structure of the bilaminar zone in the human temporomandibular joint: a light and scanning electron microscopy study in young and elderly subjects. J. Oral. Rehabil., 28:113-9, 2001.

Bernhardt, O.; Gesch, D.; Schwahn, C.; Bitter, K.; Mundt, T.; Mack, F.; Kocher, T.; Meyer, G.; Hensel, E. \& John, U. Signs of temporomandibular disorders in tinnitus patients and in a population-based group of volunteers: results of the study of health in Pomerania. J. Oral. Rehabil., 31:311-9, 2004.

Clément, C.; Bravetti, P.; Plénat, F.; Foliguet, B.; Haddioui, A. E.; Gaudy J. F. \& Weissenbach, M. Quantitative analysis of the elastic fibers in the human temporomandibular articular disc and its attachments. Int. J. Oral. Maxillofac. Surg., 35(12):1120-6, 2006.

Fujita, S.; lizuka, T. \& Dauber, W. Localization of keratan sulphate and chondroitin-6-sulphate on the anteriorly displaced human temporomandibular joint disc-histological and immunohistochemycal analysis. J. Oral. Rehabil., 28:962-970, 2001.
Tuz, H. H.; Onder, E. M. \& Kisnisci, R. S. Prevalence of otologic complaints in patients with temporomandibular disorders. Am. J. Orthop. Dentofacial. Orthop., 1:620-3, 2003.

Kino, K.; Ohmura, Y. \& Amagasa, T. Reconsideration of the bilaminar zone in the retrodiskal area of the temporomandibular joint. Oral. Surg. Oral. Med. Oral. Pathol., 75:410-21, 1993.

Leonardi, R.; Loreto, C.; Barbato, E.; Polimeni, A.; Caltabiano, R. \& Lo Muzio, L. A histochemical survey of the human temporomandibular joint disc of patients with internal derangement without reduction. J. Craniofac. Surg., 18(6):1429-33, 2007.

Minarelli, A. M. \& Liberti, E. A. A microscopic survey of the human temporomandibular joint disc. J. Oral. Rehabil., 24:835-40, 1997.

Okesson, J. P. Bell's Orofacial Pains. $5^{\text {th }}$ ed. Chicago, Quintessence Publishing C.O., 1995. p.500.

Ramírez, L. M.; Sandoval, G. P. \& Ballesteros, L. E. Los desórdenes témporomandibulares: clínica cráneo-cervicofacial. Med. Oral. Patol. Oral. Cir. Bucal., 10:E18-E26, 2005.

Sato, S.; Goto, S.; Koeda, S. \& Motegi. K. Changes of the elastic fibre network of the rabbit temporomandibular joint following disectomy. J. Oral. Rehabil., 29:847-52, 2002.

Scapino, R. P.; Obrez, A. \& Greising, D. Organization and function of the collagen fiber system in the human temporomandibular joint disk and its attachments. Cells Tissues Organs, 182(3-4):20125, 2006. 
OYANGUREN, F. R.; WURGAFT, D. R. \& MONTENEGRO, R. M. A. Evaluación histológica e histoquímica de las fibras colágenas y elásticas de los tejidos de la ATM humana. Int. J. Odontostomat., 4(3):277-284, 2010.

Wurgaft, R. \& Montenegro, M. A. Desarrollo y estructura de la articulación témporomandibular. $1^{\text {a }}$ ed. Santiago, Chile, Editorial Servimpres Ltda., 2003. p.203.

Wurgaft, R.; Pino, C.; Díaz, W. Liberona, A. \& Montenegro, M. A. Biomecánica de la articulación Témporomandibular. Rev. Chil. Ortodoncia., 18:614, 2001.
Dirección para correspondencia:

Dra. Rocío Oyanguren Figueroa.

Bartolo Soto 3911 Dpto 102

Santiago

CHILE

Fono: 56-2-7616792/ 09-6992499.

Email: draroyanguren@gmail.com

Recibido : 28-09-2010

Aceptado: 02-10-2010 